\title{
Effect of Fiber Insertion on Cuspal Deflection and Microleakage of Resin Composite: An In Vitro Study
}

\author{
Khaled Mohamed Noaman, Ibrahim El Dessoky Mostafa, Mohamed Ahmed Ali Basha* \\ Department of Operative Dentistry - Faculty of Dental Medicine, Al-Azhar University, Cairo \\ * Corresponding author: Mohamed Ahmed Ali Basha, Mobile: (+20)1066467894, E-mail: \\ dr.mohammed.basha.89@gmail.com
}

\begin{abstract}
Background: Although resin composites are now the material of choice for most restorations, polymerization shrinkage remains a major deficiency and key shortcoming that complicate the use of such versatile restorative materials. Objective: The current study was designed to investigate the efficacy of fiber insert application on the cuspal deflection and microleakage of (MOD) cavities of bicuspids restored with resin composite restorations.

Material and Methods: A total of 120 upper premolar teeth were selected and used in the present study. Each tooth was vertically embedded into self-curing acrylic resin where, the CEJ was kept $2 \mathrm{~mm}$ above the level of acrylic resin to mimic the alveolar bone support in healthy tooth. Forty premolars were used for cuspal deflection measurement and one hundred and twenty for microleakage assessment.

Results: Cuspal deflection was significantly decreased of tooth restored with Ceram.X $(0.0085 \pm 0.0031)$ using fiber inserts than that restored with Ceram.X resin composite only $(0.0145 \pm 0.009)$ at $(\mathrm{P}=0.032)$. Fiber inserts significantly decreased the cuspal deflection of tooth restored with Z350XT resin composite $(0.0076 \pm 0.0015)$ than that restored without fiber inserts for the same material $(0.0122 \pm 0.0051)$ at $(\mathrm{P}=0.002)$.

Conclusion: It could be concluded that the problem of cuspal deflection and microleakage in complex cavities prepared in premolars can be greatly reduced using fiber reinforced composite inserts. Nano filled composite with or without fiber insert has a better performance in cuspal deflection and microleakage than nanohyprid composite.

Keywords: Fiber insertion, Cuspal deflection, microleakage, Resin composite
\end{abstract}

\section{INTRODUCTION}

During polymerization if the adhesive strength exceeds the contraction stress, there is no detachment but the restoration maintains an internal tension that pulls the walls of the tooth together, reducing the intercuspal distance resulting in the phenomenon of cusp deflection ${ }^{(\mathbf{1})}$. Tooth flexure is indicative of a combination of stress in the tooth, in the restoration or across the tooth restoration interface. Postoperative sensitivity by fluid flow in exposed dentinal tubules has been associated with cuspal deflection due to the formation or propagation of enamel cracks at the interface between the tooth and the restoration as a result of bending ${ }^{(2)}$.

On the other hand, if these destructive stresses are far beyond adhesive bond strength, this compromise the synergism at the interface possibly leading to bacterial microleakage, marginal discoloration, secondary caries and pulpal inflammation or necrosis ${ }^{(3)}$.

Compensation for polymerization shrinkage is still un solved problem, which has to be addressed thoroughly to produce professionally acceptable results. Strategies suggested to minimize shrinkage stresses of composite include incremental placement technique to reduce configuration factor (C-factor), soft cure or pulse delay cure methods to slow polymerization by more gradually increasing light intensity from the curing units, and the use of low modulus intermediate liner material such as flowable composites to absorb shrinkage stresses ${ }^{(\mathbf{4})}$. Among the methods employed to reduce polymerization shrinkage in directly placed resin composite restorations is to replace a significant portion of the composite with shrink-free inserts prior to polymerization procedure ${ }^{(5)}$.

The insert technology has become the focus of increased interest especially after the introduction of resin composite glass fibers. They are translucent in color and possess stress absorption and distribution capabilities owing to their dentin like modulus of elasticity. They contain a high percentage of glass fibers embedded in a polymer matrix which is either fully or partially polymerized. They are composed of different types of glass; electrical glass (E-Glass), high strength glass (S Glass), alkaline resistance glass (AR-Glass), or quartz glass (Q- Glass), which are claimed to perform bonding to the directly packed resinous matrix either through chemical interdiffusion or micro mechanical interlocking ${ }^{(6)}$.

The aim of the present study was directed to investigate the efficacy of fiber insert application on cuspal deflection and microleakage of MOD cavities of maxillary premolars restored with resin composite restorations.

\section{MATERIAL AND METHODS}

This study included a total of total 120 sound human upper premolar teeth extracted for orthodontic reasons or periodontal affection from subjects aged 18-36 years. This study was conducted at the Faculty of Dentistry, Al-Azhar University.

Ethical approval:

Approval of the ethical committee was obtained. 


\section{I- Materials:}

Two types of resin composites, two adhesive systems and one type of glass fiber inserts were utilized in this study.

\section{A- Resin composite material:}

1. Filtek Z350XT Universal Restorative (3M Espe), shade A3 Body: A visible light-cured methacrylate-based nano filled resin composite.

2. Ceram.X spheretch one universal (Dentsply), shade A3: A visible light-cured nano hybrid composite with pre-polymerized fillers.

\section{B-Adhesive bonding system:}

1- Single bond universal adhesive system (3M ESPE): A single component, light curing adhesive.
2- Prime\&Bond universal adhesive system (DENTSPLY): A single component, light curing adhesive.

\section{C-Fiber:}

\section{Dentapreg UFM, (Dentapreg): A pre- impregnated E-glass fiber threads.}

All products names, categories, compositions, manufacturers and batch numbers of the resin composite restorative materials, adhesive systems and E-glass fiber inserts used in the present study was listed in Table (1).

Table (1): Materials used in the study:

\begin{tabular}{|c|c|c|c|}
\hline Product name & Category & Composition & $\begin{array}{l}\text { Manufacturer and patch } \\
\text { number }\end{array}$ \\
\hline $\begin{array}{l}\text { Filtek Z350XT } \\
\text { shade A3 body }\end{array}$ & $\begin{array}{l}\text { Nano-filled } \\
\text { resin } \\
\text { composite }\end{array}$ & $\begin{array}{l}\text { Resin matrix: Bis-GMA*, Bis-EMA } \\
* *, \text { UDMA***, TEGDMA**** and } \\
\text { PEGDMA**** } \\
\text { Filler: Combination of non-aggregated } 20 \mathrm{~nm} \\
\text { silica, non-aggregated } 4-11 \mathrm{~nm} \text { zirconia, and } \\
\text { aggregated zirconia/silica cluster filler. } \\
\text { [primary particle } 5-20 \mathrm{~nm} 78.5 \% \text { by weight } \\
\text { (63.3\% by volume)]. }\end{array}$ & $\begin{array}{l}\text { 3M ESPE Dental Product } \\
\text { St. Paul, MN, USA } \\
\text { (N932955) }\end{array}$ \\
\hline $\begin{array}{l}3 \mathrm{M} \text { ESPE single } \\
\text { bond universal } \\
\text { adhesive }\end{array}$ & $\begin{array}{l}\text { Universal } \\
\text { adhesive }\end{array}$ & $\begin{array}{l}\text {-MDP****** phosphate monomer } \\
\text {-Dimethacrylate resin } \\
\text {-Vitrebond }{ }^{\mathrm{TM}} \text { copolymer } \\
\text {-Filler } \\
\text {-Ethanol } \\
\text {-Water } \\
\text {-Initiators } \\
\text {-Silane }\end{array}$ & $\begin{array}{l}\text { 3M ESPE Dental Product } \\
\text { St. Paul, MN, USA } \\
(4286383)\end{array}$ \\
\hline $\begin{array}{l}\text { CERAM X } \\
\text { Spheretech one, } \\
\text { shade, A3 }\end{array}$ & $\begin{array}{l}\text { Nano-hybrid } \\
\text { composite } \\
\text { with pre- } \\
\text { polymerized } \\
\text { fillers }\end{array}$ & $\begin{array}{l}\text { Resin matrix: poly-urethane methacrylate, } \\
\text { bis-EMA and TEGDMA, highly dispersed, } \\
\text { methacrylic } \\
\text { polysiloxane nano-particles, } \\
\text { Filler system: blend of spherical, pre- } \\
\text { polymerized SphereTECTM } \\
\text { fillers }(\mathrm{d} 3,50 \approx 15 \mu \mathrm{m}) \text {, non-agglomerated } \\
\text { barium glass and ytterbium fluoride. } \\
\text { filler load ranges from } 77-79 \text { weight- } \% \text { total } \\
(59-61 \% \text { by } \\
\text { volume) }\end{array}$ & $\begin{array}{l}\text { DENTSPLY IH Ltd- } \\
\text { Building 3, the heights, } \\
\text { Wey bridge, SURREY, } \\
\text { KT130NY, United } \\
\text { Kingdom } \\
\text { (1809000093) }\end{array}$ \\
\hline $\begin{array}{l}\text { Prime\&Bond } \\
\text { adhesive }\end{array}$ & $\begin{array}{l}\text { Universal } \\
\text { adhesive }\end{array}$ & $\begin{array}{l}\text { Bi- and multifunctional acrylate, phosphoric } \\
\text { acid modified acrylate resin, initiator, } \\
\text { stabilizer, isopropanol and water }\end{array}$ & $\begin{array}{l}\text { DENTSPLY IH Ltd- } \\
\text { Building 3, THE Heights, } \\
\text { Weybridge, surrey, } \\
\text { KT130NY, United } \\
\text { Kingdom (1802000749) }\end{array}$ \\
\hline $\begin{array}{l}\text { Dentapreg fiber } \\
\text { UFM******* }\end{array}$ & E-Glass & $\begin{array}{l}\text { (Mixture of dimethacrylates }(\approx 99 \%), \text { E-glass } \\
\text { type fibers treated with epoxy-silane (weight } \\
\text { fraction } 45-65 \% \text { ), initiators and stabilizers }(\approx \\
1 \%), \text { braided multidirectional glass fibers pre- } \\
\text { impregnated with light curing resin }\end{array}$ & $\begin{array}{l}\text { ADM, Czech Republic, } \\
\text { www.dentapreg.com } \\
\text { (UFM_34-102018) }\end{array}$ \\
\hline
\end{tabular}

* bisphenol A-glycidyl methacrylate, ** ethoxylated bisphenol A glycol Dimethacrylate, *** urethane Dimethacrylate, **** triethylene glycol Dimethacrylate, ***** Polyethylene glycol Dimethacrylate

$* * * * * * 10-$ Methacryloyloxydecyl dihydrogen phosphate, $* * * * * * *$ Ultra fine mesh 


\section{II- Methods:}

\section{Selection of teeth:}

The selected teeth were free from decay, cracks, restorations and any developmental or deformative defects. Extrinsic stains or calculus deposits on teeth were cleaned using ultrasonic scaler and polished with eugenol free pumice with rotating brush at conventional speed; the specimens were stored in normal saline, which is changed every week until usage $^{(7)}$.

The teeth had regular occlusal anatomy and almost standard crown sizes (Buccolingual width range $(9 \pm$ $0.6 \mathrm{~mm})$ and mesiodistal width range $(8 \pm 0.5 \mathrm{~mm})$, which were measured with a digital caliper.

\section{Preparation of the mold and mounting of the} teeth:

Root surfaces were marked $2 \mathrm{~mm}$ below the crown margin to simulate the biologic width and to mimic the alveolar bone support in healthy tooth ${ }^{(8)}$. Specimens were then imbedded in auto-polymerizing acrylic resin (charm temp, USA) surrounded by a cylindricalshaped plastic mold (internal diameter $16.5 \mathrm{~mm}$, external diameter 21.5 . height $9.6 \mathrm{~mm}$ ) with the long axis of the tooth parallel to the plane of the acrylic resin mold.

\section{Grouping of the specimens:}

The selected teeth were randomly divided into two main groups $A$ (number of each=60) according to composite types:

Group A 1: Cavities were restored with Filtek Z350XT Universal Restorative.

Group A 2: Cavities were restored with Ceram.X sphertech one universal.

Each main group were divided in to two groups B (number of each=30) according to fiber insertion or not.

Group B 1: Samples restored with composite resin (control group)

Group B 2: Samples restored with fiber inserts/composite resin.

Each group were divided in to 3 sub-groups $\mathbf{C}$ (number of each $=10$ ) according to storage periods.

Group C 1: One day storage period.

Group C 2: One month storage period.

Group C 3: Three months storage period.

All materials used in this study were manipulated according to manufacturer's instructions.

Cusp deflection was measured first on 10 samples from sub group (Group C 1), (N total=40).

All of the specimens were stored in distilled water at room temperature till the end of storage periods.

\section{Preparation of the teeth:}

Standardized (MOD) cavities were prepared with a carbide parallel sided fissure bur \#314-010 (EMIL LANGE, Germany) in a high-speed hand piece under water coolant, with each bur being replaced after every five preparations ${ }^{\left({ }^{(9)}\right.}$ (Fig.1).

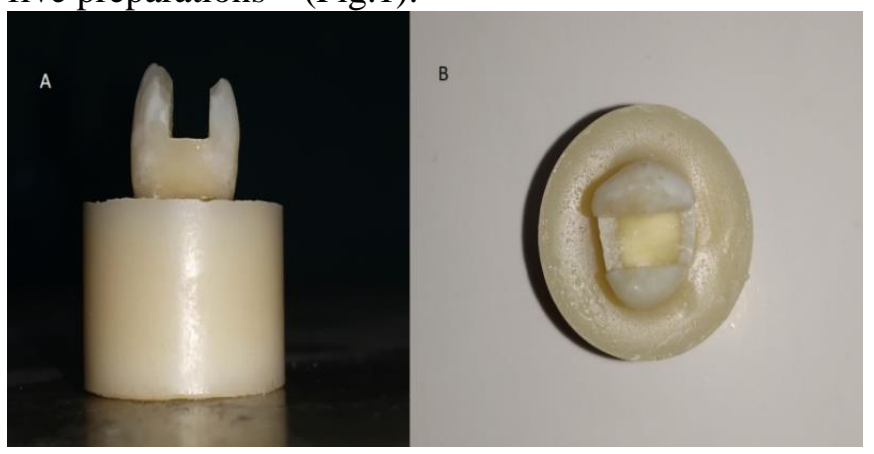

Figure (1): Standardized MOD cavity (A, Lateral view, B, Occlusal view)

\section{Restorative application:}

\subsection{Application of adhesive system:}

\section{1.a: Selective etch procedure:}

Phosphoric acid etching gel 37\% (3M ESPE scotchbond etching gel) was applied for $15 \mathrm{sec}$ to the prepared tooth structure (enamel) as recommended by manufacturer's instructions (Fig 2), then rinsed thoroughly with water for $10 \mathrm{sec}$. and gently dried; without over dryness in a way that moist condition of the dentin was preserved.

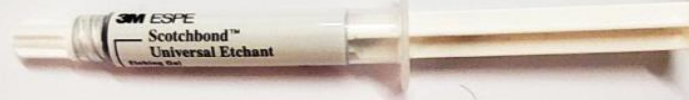

Figure (2): 3M ESPE scotchbond etching gel

\section{1.b: Adhesive application:}

Single bond universal adhesive system was applied to the prepared cavities in a rubbing motion for 20 seconds with disposable applicator according to manufacturer's instructions. The excess solvent was removed by gentle air drying for 5 seconds until there was no movement of the adhesive film and the surface should maintain a uniform glossy appearance. 5.2. Application of resin composite:

Cavities were encircled with a metallic matrix band held firmly by matrix retainer (Tofflemire, USA) against the proximal aspects on the teeth being restored ${ }^{(\mathbf{1 0}, \mathbf{1 1})}$. Cavities were then restored with resin composite. The bands were changed for each restoration.

\section{2.a. Composite application:}

In the groups of resin composite restoration without insert application, cavities were restored with horizontal layering technique in two increments, the first layer start from the cavity floor up to half the cavity depth (1.5 mm thickness) which was verified using periodontal probe and the second completing the restoration. The occlusal aspect of the restoration was 
sculptured to approximate the occlusal anatomy of a maxillary premolar teeth. Each increment was separately cured for 40 seconds each from the occlusal aspect. After removing the matrix, all the restorations were light cured additionally from the buccal and lingual direction for 40 seconds.

\section{2.b. Composite / Fiber application:}

In the group of resin composite restoration with insert application, the pre-impregnated E-glass fiber insert is a uniform thread with 0.1 thickness, $4-10 \mathrm{~mm}$ width and $60 \mathrm{~mm}$ long. Thus, the inserts were cut to fit the mesio-distal dimensions of the specimens.

\subsection{Finishing and polishing of restorations:}

The restored maxillary premolar teeth were finished and polished using graded series of flexible discs Sof-Lex (3M ESPE, St., Paul, USA).

\section{Cuspal deflection measurements:}

Cusp deflection were measured after cavity preparation and before restoration, and once more after five minutes of restoration.

\subsection{Measurement of intercuspal distance before restoration:}

Each tooth was secured to a micrometer stage of universal horizontal metroscope, which was the equipment used for calibration providing a level of confidence of approximately $95 \%$. The cuspal indices were in contact with measuring device prop. Then, the intercuspal distance was measured between these two reference points. This was considered the intercuspal distance $(\mathrm{C} 1 \mathrm{a})$ before restoration of the cavities.

\section{2. Measurement of the intercuspal distance after restoration:}

The intercuspal distance was measured again, after five minutes after complete polymerization of resin composite to give the second reading $(\mathrm{C} 1 \mathrm{~b})$. The difference between the first and the second readings was considered the cuspal deflection after five minutes from the completion of restoration.

\section{Microleakage evaluation:}

Microleakage was evaluated at 3 periods intervals (one day one month and three months). After cusp deflection measurements, samples of subgroup (C1) were evaluated for microleakage after one-day storage, samples of subgroup (C2) were evaluated after one month storage and samples of subgroup (C3) were evaluated after three months of storage to measure micro leakage.

After demounting the teeth from the resin blocks, the restored teeth then dried thoroughly. The teeth were coated with two layers of an acid- resistant protective nail varnish except for an area approximately $1 \mathrm{~mm}$ around the margin of the restorations. The nail varnish was allowed to dry for 4 hours, to prevent silver penetration throughout the apical foramen, Fig (3).

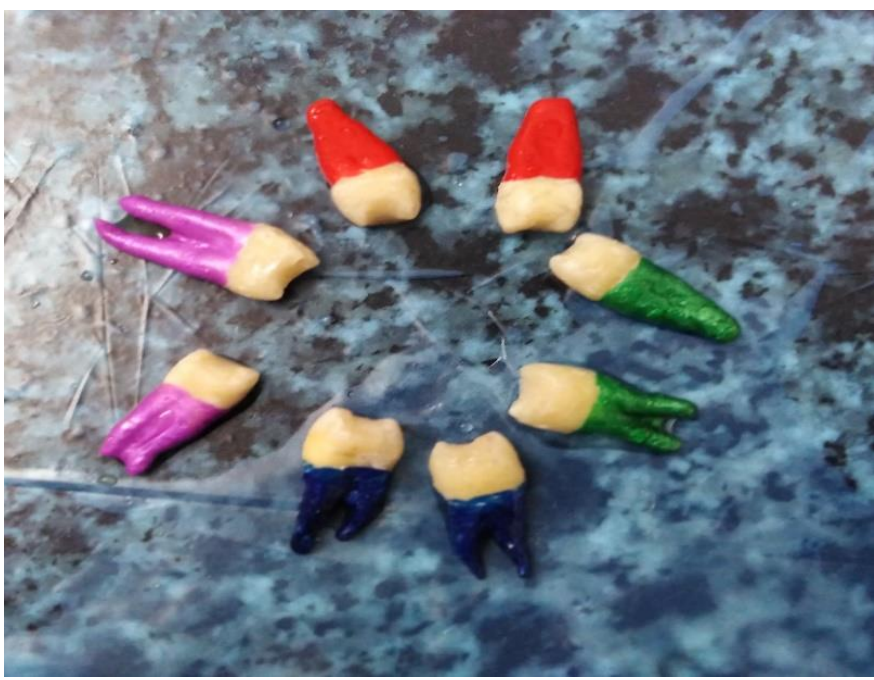

Figure (3): Sealing of the tooth apex with nail varnish

\section{1. Silver nitrate preparation:}

The teeth were then placed in a $50 \mathrm{wt} \%$ silver nitrate aqueous solution for $2 \mathrm{hr}$ in total darkness ${ }^{(12)}$. Following retrieval, they were rinsed in running distilled water for $30 \mathrm{~min}$, immersed in photo developing solution (kodak), and exposed to a fluorescent light for $6 \mathrm{hr}$ so that silver ion reduction would be completed. After removal from the developing solution, the teeth were rinsed thoroughly in running water and immersed in acetone for $20 \mathrm{~min}$ to dissolve the layer of nail varnish ${ }^{(\mathbf{1 3})}$.

\subsection{Sectioning of teeth:}

Teeth were sectioned longitudinally in MD direction through the middle of the restoration using a diamond disc at low speed with water coolants. Fig (4).

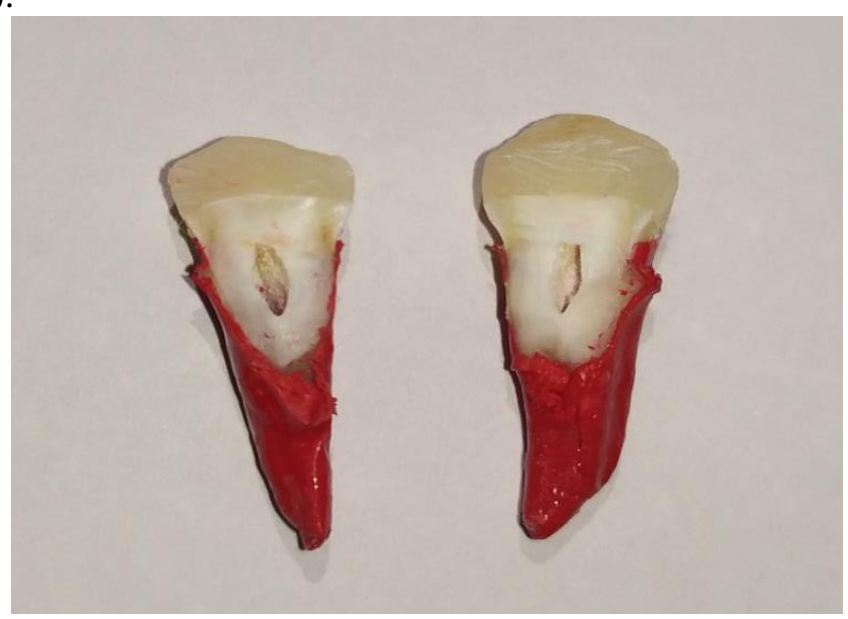

Figure (4): A photograph showing sample after sectioning.

\subsection{Scanning electron microscope examination:}

At the end of storage periods (one day and 1 month and three months), samples were used for scanning electron microscope examination and also analyzed using Energy dispersive X-ray spectrometry (EDX) to evaluate microleakage. The cut surfaces of each half were ground and polished to high gloss with wet silicon carbide sandpaper to avoid deterioration of electron 
beam of SEM, the holder with the specimen in place was mounted in scanning microscope (JSM-5500 LV; JEOL Ltd - Japan). The surfaces of specimens were examined under scanning electron microscope at 20 KV. Photomicrographs were taken at magnifications X200 to assess the microleakage. Amount of silver grains that was penetrated at resin-dentin interface was calculated and statistically analyzed through energy levels of EDX analysis.

\section{8-Statistical analysis:}

Data was represented by mean, standard deviation (SD), median (M), standard error deviation range (SED) with 95\% Confidence Interval (95\% CI) values. Repeated measures ANOVA test was used to compare between different types of composite and storage period. Post hoc tuckey test was used for comparison between different groups showing significance.

\section{RESULTS}

Mean, standard deviation (SD), median (M), standard error deviation range (SED) with 95\% Confidence Interval (95\% CI) values of cusp deflection after restoration with different resin composite with and without fiber insertion will be presented in tables $(1,2,3)$ and illustrated in figures $(16,17,18)$. While the microleakage of different resin composite with and without fiber insertion will be presented in tables $(1,2,3)$ and illustrated at different storage periods.

Repeated measures ANOVA test was used to compare between different types of composite and storage period.

Post hoc tuckey test was used for comparison between different groups showing significance.

The significance level was set to $\mathrm{P} \leq 0,05$. Statistical analysis was performed with IBM@* SPSS ${ }^{\Theta}$ Statistics Version 20 at $95 \%$ confidence interval.

\section{Cuspal deflection:}

There is a significant difference between Ceram $\mathrm{x}$ and Ceram.X+Fiber, Z350 XT+Fiber also there is no significant difference between Ceram.X and Z350XT. While there is a significant difference between Z350XTand Z350XT+fiber, Ceram. X+Fiber, and there is no significant difference between Ceram.X and Z350XT. Table (2).

\section{I- Effect of restorative material on cusp deflection:}

\section{I.a. Without fiber insertion:}

Cuspal deflection of tooth restored with Ceram.X without fiber insertion $(0.0145 \pm 0.009)$ was higher than that restored with Z350XT $(0.0122 \pm 0.0051)$ but no significant difference. $(\mathrm{P}$ value $=0.07$ )

\section{I.b. With fiber insertion:}

There was no significant difference in cuspal deflection at $(\mathrm{P}$ value $=0.06)$ between tooth restored with Ceram $x$ resin composite $(0.0085 \pm 0.0031)$ and these restored with Z350XT $(0.0076 \pm 0.0015)$.

Table (2): Effect of different types of composite on cuspal deflection

\begin{tabular}{|c|c|c|c|}
\hline \multicolumn{4}{|c|}{ CUSPAL DEFLECTION } \\
\hline & Mean & SD & $P$ value \\
\hline Ceram.X & $\mathrm{0.0145}^{\mathrm{a}}$ & 0.009 & \multirow{4}{*}{$0.01^{*}$} \\
\hline Ceram $/ \mathbf{X}+\mathbf{F}$ & $0.0085^{a b}$ & 0.0031 & \\
\hline Z350XT & $0.0122^{a}$ & 0.0051 & \\
\hline Z350XT+F & $0^{0.0076}{ }^{\mathrm{ab}}$ & 0.0015 & \\
\hline
\end{tabular}

* significance $\mathrm{p}<0,05$.

\section{II- Effect of fiber insert for different types of composite on cusp deflection: \\ II.a. Ceram.X}

Cuspal deflection was significantly decreased of tooth restored with Ceram.X $(0.0085 \pm 0.0031)$ using fiber inserts than that restored with Ceram.X resin composite only $(0.0145 \pm 0.009)$ at $(\mathrm{P}=0.032)$. table $(3)$

Table (3): Effect of Fiber application for Ceram $x$ on cuspal deflection

$\mid$\begin{tabular}{l|l|l|l|}
\hline CUSP DEFLECTION \\
\hline & Mean & SD & P value \\
\hline Ceram.X & 0.0145 & 0.009 & \multirow{2}{*}{0.032} \\
\hline Ceram.X +F & 0.0085 & 0.0031 & \\
\hline
\end{tabular}

$*$ significance $\mathrm{p}<0,05$.

\section{II.b. Z350XT}

Fiber inserts significantly decreased the cuspal deflection of tooth restored with Z350XT resin composite $(0.0076 \pm 0.0015)$ than that restored without fiber inserts for the same material $(0.0122 \pm 0.0051)$ at $(\mathrm{P}=0.002)$. Table (4)

Table (4): Effect of Fiber application for Z350XT on cuspal deflection

\begin{tabular}{|l|l|l|l|}
\hline \multicolumn{1}{|l|}{ CUSP DEFLECTION } \\
\hline & Mean & SD & P value \\
\hline Z350XT & 0.0122 & 0.0051 & 0.002 \\
Z350XT + F & 0.0076 & 0.0015 & \\
\hline
\end{tabular}

$*$ significance $\mathrm{p}<0,05$.

\section{Microleakage:}

\section{Effect of fiber insertion on microleakage:}

Microleakage was significantly decreased in tooth restored with resin composite Z350XT with fiber insertion than that restored with resin composite only at $\mathrm{P}=0.008$ for storage periods (one day, one month and three months). Also, tooth restored with Ceram.X+Fiber insertion at different storage periods (one day, one month and three months) showed a significant decrease in microleakage $(\mathrm{P}=0.002)$ than that restored with Ceram.X only. Table (5) 
Table (5): Comparison between effect of fiber insertion on microleakage

\begin{tabular}{|c|c|c|c|c|c|c|c|c|}
\hline & \multicolumn{2}{|l|}{ One day } & \multicolumn{2}{|c|}{ One month } & \multicolumn{2}{|c|}{ Three months } & \multirow{2}{*}{$\mathbf{P}$} \\
\hline & & Mean & SD & Mead & SD & Mean & SD & \\
\hline \multirow{2}{*}{ Fiber } & Ceram.X & 1.251667 & 0.088296 & 2.048333 & 0.085417 & 2.715 & 0.078602 & \multirow{2}{*}{0.004} \\
\hline & $\mathrm{Z350} \mathrm{XT}$ & 0.608333 & 0.025744 & 1.231667 & 0.042065 & 2.593333 & 0.13485 & \\
\hline \multirow{2}{*}{$\begin{array}{l}\text { No } \\
\text { Fiber }\end{array}$} & Ceram.X & 1.766667 & 0.133957 & 2.308333 & 0.145772 & 4.446667 & 0.204999 & \multirow{2}{*}{0.002} \\
\hline & Z350XT & 1.013333 & 0.06059 & 1.605 & 0.056377 & 3.271667 & 0.17779 & \\
\hline
\end{tabular}

* significance $\mathrm{p}<0,05$.

\section{Effect of different composite resin type on microleakage:}

There was statistically significant difference between Ceram.X and Z350XT resin composites in microleakage scores, where Ceram.X show higher microleakage than Z350XT $(\mathrm{P}=0.0012)$ of the same storage period. Also, microleakage scores was significantly higher $(\mathrm{P}=0.032)$ for tooth restored with Ceram.X+Fiber than that of Z350XT+Fiber at the same storage period. Table (6)

Table (6): Comparison between effect of composite types on microleakage

\begin{tabular}{|c|c|c|c|c|c|c|c|c|}
\hline & \multicolumn{2}{|l|}{ One day } & \multicolumn{2}{|c|}{ One month } & \multicolumn{2}{|c|}{ Three months } & \multirow{2}{*}{$\mathbf{P}$} \\
\hline & & Mean & SD & Mean & SD & Mean & SD & \\
\hline \multirow{2}{*}{ Ceram.X } & $\begin{array}{l}\text { No } \\
\text { fiber }\end{array}$ & 1.766667 & 0.133957 & 2.308333 & 0.145772 & 4.446667 & 0.204999 & \multirow{4}{*}{0.003} \\
\hline & $\begin{array}{l}\text { With } \\
\text { fiber }\end{array}$ & 1.251667 & 0.088296 & 2.048333 & 0.085417 & 2.715 & 0.078602 & \\
\hline \multirow{2}{*}{ Z350XT } & $\begin{array}{l}\text { No } \\
\text { fiber }\end{array}$ & 1.013333 & 0.06059 & 1.605 & 0.056377 & 3.271667 & 0.17779 & \\
\hline & $\begin{array}{l}\text { With } \\
\text { fiber }\end{array}$ & 0.608333 & 0.025744 & 1.231667 & 0.042065 & 2.593333 & 0.13485 & \\
\hline
\end{tabular}

* significance $\mathrm{p}<0,05$.

\section{Effect of storage period on microleakage:}

For one day storage period, Ceram.X showed higher statistically significant difference $(1.766667 \pm 0.133957)$ than Z350XT (1.013333 \pm 0.06059$)$ at $P=0.017$. Also, Ceram. X+Fiber showed higher statistically significant difference $(1.251667 \pm 0.088296)$ than Z350XT+Fiber $(0.608333 \pm 0.025744)$ at $\mathrm{P}=0.001$. For one month storage period, Ceram $x$ showed higher statistically significant difference $(2.308333 \pm 0.145772)$ than Z350xt $(1.605 \pm 0.056377)$ at $\mathrm{P}=0.019$. Also, Ceram.X+Fiber showed higher statistically significant difference $(2.048333 \pm 0.085417)$ than $\mathrm{Z} 350 \mathrm{XT}+$ Fiber $(1.231667 \pm 0.042065)$ at $\mathrm{P}=0.023$. For three months storage period, Ceram.X showed higher statistically significant difference (4.446667 \pm 0.204999$)$ than Z350XT (3.271667 \pm 0.17779$)$ at $P=0.033$. Also, Ceram.X+fiber showed higher statistically significant difference $(2.715 \pm 0.078602)$ than Z350XT+Fiber $(2.593333 \pm 0.13485)$ at $\mathrm{P}=0.014$. These results were shown in table (7).

Table (7): Comparison between effect of storage periods on microleakage.

\begin{tabular}{|c|c|c|c|c|c|c|c|c|c|}
\hline & \multicolumn{4}{|l|}{ Ceram.X } & \multicolumn{4}{|l|}{ Z350XT } & \multirow{3}{*}{$\mathbf{P}$} \\
\hline & \multicolumn{2}{|l|}{ No fiber } & \multicolumn{2}{|c|}{ With fiber } & \multicolumn{2}{|l|}{ No fiber } & \multicolumn{2}{|l|}{ Vith fiber } & \\
\hline & Mean & SD & Mean & SD & Mean & SD & Mean & SD & \\
\hline One day & 1.766667 & 0.133957 & 1.251667 & 0.088296 & \begin{tabular}{l|l}
5 & 1.013333 \\
\end{tabular} & 0.06059 & 0.608333 & 0.025744 & 0.01 \\
\hline One month & 2.308333 & 0.145772 & 2.048333 & 0.085417 & $\begin{array}{l}7.605 \\
\end{array}$ & 0.056377 & 1.231667 & 0.042065 & 0.023 \\
\hline $\begin{array}{l}\text { Three } \\
\text { months }\end{array}$ & 4.446667 & 0.204999 & 2.715 & 0.078602 & \begin{tabular}{l|l}
2 & 3.271667
\end{tabular} & 0.17779 & 2.593333 & 0.13485 & 0.42 \\
\hline
\end{tabular}

* significance $\mathrm{p}<0,05$.

\section{DISCUSSION}

In the current study two types of resin composite restorations were employed which were nano filled and Nanohybrid resin composites $(3 \mathrm{M}$ filtek Z350XT \& ceram.X sphertech one) comprising features of nano-optimized technology, which means that particles in the nano-scale range have been added to optimize its resin properties, This was to focus precisely on the effect of insert utilized.

Many attempts were made in order to reduce cusp deflection, many material factors that may influence 
cuspal deflection among of these factors polymerization shrinkage and flowability of the composite resin, use of liner, filling technique (bulk vs incremental technique), restoration methods (direct vs indirect) and method of light curing. Depending on the method of measurement, cavity size and the amount of composite polymerization shrinkage, silorane-based lowshrinking composite resins have been introduced in an attempt to decrease polymerization shrinkage and stress at tooth-restoration interface.

Over the past few years, new dental products containing glass, polyethylene, quartz carbon, or other fibers have been made available. These products are meant to improve the mechanical properties of the materials and provide extended applications for resin composites. Glass fibers have demonstrated their ability to withstand tensile stress and stop crack propagation in composite material ${ }^{(\mathbf{1 4})}$.

In the present study we use E-glass fiber due to the following advantages: Low cost, relatively low density, Able to maintain strength properties over a wide range of conditions, relatively insensitive to moisture, Chemical and heat-resistant, form a good bond with dental composite. Moreover, the insert was placed between the two increments, since this would result in shorter working arm, according to levers principles. Thus, better load bearing and resistance could be expected.

\section{Cusp deflection:}

\section{I.1 Effect of restorative material on cusp deflection}

In general, the results of the current study revealed the occurrence of inward movement post curing in all specimens. This cuspal deflection may be related to the loss of tooth rigidity, when the marginal ridges were removed in MOD cavities allowing for tooth deformation. When the continuity of the enamel is lost due to cavity preparation, the properties of the dentine play a major role in cusp behavior.

The polymerization shrinkage of composites in a cavity generates stress that can be transmitted via the adhesive interface to adjacent dental tissues, producing dental deformation. The degree of stress generated at the interface is influenced by the $\mathrm{C}$-factor. This was in accordance with Gonzalez Lopez et al. ${ }^{(15)}$ and Gonzalez Lopez et al. ${ }^{(8)}$.

The results of this investigation showed an inward cuspal deflection for all the specimens post light irradiation, which suggests that adhesion at the tooth/restoration interface was established to exhibit such kinetics and to cause tooth deformation by the contractile resin composite. This was in accordance with Fleming et al. ${ }^{(16)}$, Cara et al. ${ }^{(3)}$.

The polymerization shrinkage of the composite resins in all tested groups resulted in an inward deflection of the cusps, in agreement with other studies $(17,18)$.

The data from table (1) revealed that all restorative materials showed cusp deflection but
Z350XT show cusp deflection lower than Ceram.X, the lower amount of cusp deflection with Z350XT may be due to it has flexural strength higher than Ceram. $X^{(\mathbf{1 9})}$, because of flexural strength of nanofilled composite resins were higher as compared to that of nanohybrid composite resins ${ }^{(20)}$, this might be explained by the fact that an increase in the weight percentage of nanofiller results in an increase in the flexural strength of composite resin because a higher filler content gives rise to greater resistance to crack formation. Therefore, a better bond between the resin and filler and silanization of the filler particles result in better conduction of tensions between the matrix and filler ${ }^{(21)}$.

\section{I.2 Effect of fiber insertion on cusp deflection:}

Based on the results of the present study, the highest cuspal deflection values were recorded in cavities restored with composite resins alone. In other words, the use of fibers may decrease cuspal deflection of restored teeth. In the same context, Karbhari and Wang ${ }^{(22)}$ reported that the use of fibers along with composite resins not only increases tooth fracture resistance and decreases concerns about shrinkage but also the FRC can aid in reducing cuspal movement in MOD cavities in posterior teeth.

Generally, the results of the in vitro test in the current investigation revealed that the application of inserts in (Ceram.X sphertech one) and (3M Filtek Z350 XT) composite restoration in maxillary premolars with MOD cavities resulted in substantial reduction in the inward cuspal deflection this was presented in Table $(\mathbf{5}, \mathbf{6})$.

Alander et al. ${ }^{(23)}$ demonstrated an increase in ultimate flexural strength of composite resins with the use of composite fibers. Based on the above-mentioned discussion, it can be concluded that the use of fibers along with composite restorations may increase flexural strength and modulus of elasticity of composite resin and also decrease the cavity $\mathrm{C}$-factor effect; Donly et al. ${ }^{(24)}$ leading to lower polymerization shrinkage and cuspal deflection .

\section{Microleakage:}

\section{II.1 Effect of restorative material on microleakage:}

The results of the present study demonstrated that no material could completely eliminate micro leakage. Groups of Z350XT showed better results than Groups of ceram X. as shown in table (5), this may be due to Z350XT exhibited highest degree of conversion(DC) ${ }^{(25)}$ this may be explained by the fact to molecular composition of resin matrix of Z350XTcomposite richer in highly reactive and more flexible monomers (such as TEGDMA) which has the smallest size and highest concentration of double bonds So this monomer should exhibit the highest crosslink density and be able to form tightest networks, also it has been previously proven that combining TEGDMA and Bis-GMA in the composite formulation (as in Z350XT) allows a synergistic effect that increases the $\mathrm{DC}^{(26)}$. These finding was agreement with 
other studies who concluded that increasing Crosslinking density is associated with increased mechanical properties and stability. In addition, further conversion of monomer to polymer, limits the number of unreacted monomers that may serve as plasticizers in the polymer matrix ${ }^{(27,28)}$.

\section{II.2 Effect of fiber insertion on microleakage:}

All of MOD cavities restored with or without inserts exhibited a degree of microleakage. However, the application of insert in the resin composite restoration produced a significant reduction in the microleakage values. This was presented in table (4). this was in agreement with the finding of Palin $\boldsymbol{e t}$ al. (29), where marginal leakage was reported in all specimens, even those which showed low cusp displacement. Since polymerization shrinkage stress is dependent not only upon the volumetric shrinkage of the restorative material, but also the nature of the interfacial bond between the restorative material and the tooth structure ${ }^{(\mathbf{3 0})}$. This could be explication by creation of a change in stress dynamics accompanied by the presence of fibers ${ }^{(31)}$.

The use of inserts of similar physicochemical characteristics as the resin composite restoration, the inserts enjoyed behavior similar to that of the matrix composite. Regarding the structure of insert, it is composed of silanized E-glass fibers intensely compacted within the polymer/monomer gel matrix surrounded by a polymethyl methacrylate capsule. It represents multiphase structure known as interpenetrating polymer network (IPN). In IPN, linear polymer phases (PMMA) and cross-linked polymer phases (Bis-GMA) are not chemically bonded together, form a single network polymer. The advantages of the IPN were described as easier handling of the fiber material, high strength, reduced water sorption, high flexural strength, and improved adhesion between the FRC framework and the veneering composite after polymerization $^{(32)}$.

This is likely to diminish the possibility of stress development within the body of the cured restoration with fiber insert or the formation of voids and defects at the interface between the insert and the rest of resin composite where they acted as a monobloc system. This was confirmed by Wahab and Shaini ${ }^{\left({ }^{(9)}\right.}$.

In the current study, the microleakage assessment include storage in saline to retain dental moisture.

After specimens were stored in saline for (one day, one month, three months), they undergo microleakage test. Based on the results of the present study, the microleakage values were higher in three months than one moth than one day storage period, table (6).

This may be attributed to water sorption due to presence of hydrolytically susceptible groups in their structure, such as ester, urethane, and ether linkages, as well as hydroxyl groups. While these monomers and their resultant polymers are not considered to be extremely hydrophilic, they certainly absorb water and to a potentially damaging extent ${ }^{(135)}$, also in the present study 3M Z350XT samples show less microleakage than Ceram.X, this may be due to different filler type in both composite types. Where composites with pure silica or quartz fillers are comparatively inert in water, many composites containing radiopaque glasses have been shown to undergo greater dissolution in water and saline solutions ${ }^{(33)}$. On the contrary Sadek 2003 et al. concluded that the storage period of 3 months produced microleakage results similar to those produced after the 24-hour period which may be due to difference in storage media which is distilled water ${ }^{(34)}$.

In the current study there was a direct relation between marginal leakage and cuspal deflection i.e. an increase in cuspal deflection was associated with an increase in leakage. This can be attributed to higher associated bending of tooth composite zone and the possible microcracks formation allowing silver particle penetration. This in agreement with Abbas et al. ${ }^{(10)}$, Palin et al. ${ }^{(29)}$ and Taha et al. ${ }^{(30)}$. They proposed that the significant reduction in the cuspal deflection of the cavities corresponds to synergism at the tooth/restoration interface. However, this was in disagreement with Fleming et al $^{\left({ }^{(35)}\right.}$ and Moorthy $\boldsymbol{e t}$ al. ${ }^{(11)}$, where the reduction in the cuspal deflection values was accompanied with no change in the microleakage. This may be related to difference in test conditions.

\section{CONCLUSIONS}

\section{Under the experimental conditions of the current} study, the following conclusion was evident:

1-The problem of cuspal deflection and microleakage in complex cavities prepared in premolars can be greatly reduced using fiber reinforced composite inserts.

2- Nano filled composite with or without fiber insert has a better performance in cuspal deflection and microleakage than nanohybrid composite.

3- Aging of resin composite (nano filled and nano hybrid) with or without fiber insert up to three months have a deleterious effect on microleakage.

\section{RECOMMENDATIONS}

Further investigations are needed to study the other aspects of the Insert reinforced resin composite restoration to help predicting the clinical success and long-term serviceability of such technology.

\section{REFERENCES}

1. Gonzalez-Lopez S, Lucena-Martin C, De Haro-Gasquet F, Vilchez-Diaz M, De Haro-Munoz C (2004): Influence of different composite restoration techniques on cuspal deflection: An in vitro study. Oper Dent., 29(6):656-60. 
2. Ratih D, Palamara J, Messer H (2007): Dentinal fluid flow and cuspal displacement in response to resin composite restorative procedures. Dent Mater., 23(11):1405-11.

3. Cara R, Fleming G, Palin W, Walmsley A, Burke F (2007): Cuspal deflection and microleakage in premolar teeth restored with resin-based composites with and without an intermediary flowable layer. J Dent., 35(6):482-9.

4. Lee M, Cho B, Son H, Um C, Lee I (2007): Influence of cavity dimension and restoration methods on the cusp deflection of premolars in composite restoration. Dent Mater., 23(3):288-95.

5. Federlin M, Thonemann B, Schmalz G (2000): Insertsmegafillers in composite restorations: A literature review. Clin Oral Investig., 4(1):1-8.

6. Chieruzzi M, Pagano S, Pennacchi M, Lombardo G, D'Errico P, Kenny J (2012): Compressive and flexural behavior of fibre reinforced endodontic posts. J Dent., 40(11):968-78.

7. Cobankara F, Terlemez A, Orucoglu H (2008): Maxillary first molar with an unusual morphology: report of a rare case Oral Surg Oral Med Oral Pathol Oral Radiol Endod., 106(6): 62-5.

8. González-López S, Díaz M, Haro-Gasquet D, Ceballos L, Haro-Muñoz D (2007): Cuspal flexure of teeth with composite restorations subjected to occlusal loading. J Adhes Dent., 9(1):11-5.

9. Wahab F, Shaini F, Morgano S (2003): The effect of thermocycling on microleakage of several commercially available composite Class V restorations in vitro. J Prosthet Dent., 90(2):168-74.

10. Abbas G, Fleming G, Harrington E, Shortall A, Burke F (2003): Cuspal movement and microleakage in premolar teeth restored with a packable composite cured in bulk or in increments. J Dent., 31(6):437-44.

11. Moorthy A, Hogg C, Dowling A, Grufferty B, Benetti A, Fleming G (2012): Cuspal deflection and microleakage in premolar teeth restored with bulk-fill flowable resin-based composite base materials. J Dent., 40(6):500-5.

12. Wu W, Cobb E, Dermann K, Rupp N (1983): Detecting margin leakage of dental composite restorations. J Biomed Mater Res., 17(1):37-43.

13. Tay F, Gwinnett A, Pang K, Wei $S$ (1995): Variability in microleakage observed in a total-etch wet-bonding technique under different handling conditions. J Dent Res., 74(5):116878.

14. Dhingra V, Taneja S, Kumar M, Kumari M (2014): Influence of fiber inserts, type of composite, and gingival margin location on the microleakage in Class II resin composite restorations. Oper Dent., 39(1): 9-15.

15. González López S, Sanz Chinesta M, Ceballos García L, de Haro Gasquet F, González Rodríguez M (2006): Influence of cavity type and size of composite restorations on cuspal flexure. Med Oral Patol Oral Cir Bucal., 11(6):536-40.

16. Fleming G, Cara R, Palin W, Burke F (2007): Cuspal movement and microleakage in premolar teeth restored with resin-based filling materials cured using a 'soft-start' polymerization protocol. Dent Mater., 23(5):637-43.

17. Karaman E, Ozgunaltay G (2013): Cuspal deflection in premolar teeth restored using current composite resins with and without resin-modified glass ionomer liner. Oper Dent., 38(3):282-9.

18. Bouillaguet $\mathbf{S}$, Gamba J, Forchelet J, Krejci I, Wataha J (2006): Dynamics of composite polymerization mediates the development of cuspal strain. Dent Mater., 22(10):896-902.
19. Hegde M, Shetty S, Hegde N, Kumari S, Sanjeev G, Patodiya A (2014): Effect of electron beam irradiation on flexural strength of two nanocomposites-An In vitro Study. J Adv Med Med Res., 2014:4654-64.

20. Fischer J, Roeske S, Stawarczyk B, Haemmerle C (2010): Investigations in the correlation between Martens hardness and flexural strength of composite resin restorative materials. Dent Mater J., 29(2):188-92.

21. Safaee S, Yasrebi B (2017): Effect of an increase in nanofiller content on the mechanical properties of high-leucite composite resins useable in dentistry. Cres J Med and Bio Sci., 4(3):144-49.

22. Karbhari V, Wang Q (2007): Influence of triaxial braid denier on ribbon-based fiber reinforced dental composites. Dent Mater., 23(8):969-76.

23. Alander P, Lassila L, Tezvergil A, Vallittu P (2004): Acoustic emission analysis of fiber-reinforced composite in flexural testing. Dent Mater., 20(4):305-12.

24. Donly K, Wild T, Bowen R, Jensen M (1989): An in vitro investigation of the effects of glass inserts on the effective composite resin polymerization shrinkage. J Dent Res., 68(8):1234-7.

25. Habib A, Waly G, Nour A (2018): The degree of conversion and class II cavity microleakage of different bulk fill composites placed with different restorative techniques. Fut Dent J., 4(2):231-38.

26. Gonçalves F, Kawano Y, Pfeifer C, Stansbury J, Braga R (2009): Influence of BisGMA, TEGDMA, and BisEMA contents on viscosity, conversion, and flexural strength of experimental resins and composites. Eur J Oral Sci., 117(4):442-6.

27. Barszczewska-Rybarek I (2009): Structure-property relationships in dimethacrylate networks based on Bis-GMA, UDMA and TEGDMA. Dent Mater., 25(9):1082-9.

28. Kusgoz A, Ülker M, Yesilyurt C, Yoldas O, Ozil M, Tanriver M (2011): Silorane- based composite: Depth of cure, surface hardness, degree of conversion, and cervical microleakage in Class II cavities. J Esthet Restor Dent., 23(5):324-35.

29. Palin W, Fleming G, Nathwani H, Burke F, Randall $R$ (2005): In vitro cuspal deflection and microleakage of maxillary premolars restored with novel low-shrink dental composites. Dent Mater., 21(4):324-35.

30. Taha N, Palamara J, Messer H (2009): Cuspal deflection, strain and microleakage of endodontically treated premolar teeth restored with direct resin composites. J Dent., 37(9):72430 .

31. Oskoee P, Ajami A, Navimipour E, Oskoee S, Sadjadi J (2009): The effect of three composite fiber insertion techniques on fracture resistance of root-filled teeth. J Endod., 35(3):413-6.

32. Ilday N, Seven N (2011): The influence of different fiberreinforced composites on shear bond strengths when bonded to enamel and dentin structures. J Dent Sci., 6(2):107-15.

33. Ferracane J (2006): Hygroscopic and hydrolytic effects in dental polymer networks. Dent Mater., 22(3):211-2.

34. Sadek F, Moura S, Ballester R, Muench A, Cardoso $P$ (2003): The effect of long-term storage on the microleakage of composite resin restorations: qualitative and quantitative evaluation. Pesqui Odontol Bras., 17(3):261-6.

35. Fleming G, Hall D, Shortall A, Burke F (2005): Cuspal movement and microleakage in premolar teeth restored with posterior filling materials of varying reported volumetric shrinkage values. J Dent., 33(2):139-46. 